\title{
Managing refractory Crohn's disease: challenges and solutions
}

This article was published in the following Dove Press journal:

Clinical and Experimental Gastroenterology

10 April 2015

Number of times this article has been viewed

\section{Satoshi Tanida \\ Keiji Ozeki \\ Tsutomu Mizoshita \\ Hironobu Tsukamoto \\ Takahito Katano \\ Hiromi Kataoka \\ Takeshi Kamiya \\ Takashi Joh}

Department of Gastroenterology and Metabolism, Nagoya City University Graduate School of Medical Sciences, Aichi Prefecture, Japan
Correspondence: Satoshi Tanida Department of Gastroenterology and Metabolism, Nagoya City University Graduate School of Medical Sciences, I Kawasumi, Mizuho-cho, Mizuho-ku, Nagoya, Aichi 467-860I, Japan

$\mathrm{Tel}+8 \mid 5285382$ II

$\mathrm{Fax}+8 I 528520952$

Email stanida@med.nagoya-cu.ac.jp
Abstract: The goals of treatment for active Crohn's disease (CD) are to achieve clinical remission and improve quality of life. Conventional therapeutics for moderate-to-severe CD include 5-aminosalicylic acid, corticosteroids, purine analogs, azathioprine, and 6-mercaptopurine. Patients who fail to respond to conventional therapy are treated with tumor necrosis factor (TNF)- $\alpha$ inhibitors such as infliximab and adalimumab, but their efficacy is limited due to primary nonresponse or loss of response. It is suggested that this requires switch to another TNF- $\alpha$ inhibitor, a combination therapy with TNF- $\alpha$ blockade plus azathioprine, or granulocyte and monocyte adsorptive apheresis, and that other therapeutic options having different mechanisms of action, such as blockade of inflammatory cytokines or adhesion molecules, are needed. Natalizumab and vedolizumab are neutralizing antibodies directed against integrin $\alpha 4$ and $\alpha 4 \beta 7$, respectively. Ustekinumab is a neutralizing antibody directed against the receptors for interleukin-12 and interleukin-23. Here, we provide an overview of therapeutic treatments that are effective and currently available for CD patients, as well as some that likely will be available in the near future. We also discuss the advantages of managing patients with refractory CD using a combination of TNF- $\alpha$ inhibitors plus azathioprine or intensive monocyte adsorptive apheresis.

Keywords: adalimumab, granulocyte and monocyte adsorptive apheresis, combination therapy, complete remission

\section{Introduction}

Crohn's disease (CD) involves chronic and progressive transmural inflammation of the bowel characterized by repeated periods of remission and deterioration. Pharmacologic management of CD currently consists of 5-aminosalicylic acid (5-ASA), corticosteroids, purine analogs azathioprine (AZA), and 6-mercaptopurine (MP), and biologics including anti-tumor necrosis factor (TNF)- $\alpha$ inhibitors. Infliximab (IFX) and adalimumab (ADA) are chimeric and fully human monoclonal immunoglobulin G1 antibodies that neutralize TNF- $\alpha$. Treatment with anti-TNF- $\alpha$ antibodies like IFX and ADA can induce mucosal healing in the affected segments of the digestive tract. ${ }^{1}$ These agents have currently validated therapeutic efficacy in patients with CD. ${ }^{2-5}$ Thus, anti-TNF- $\alpha$ antibodies currently play a central role in the treatment of patients with CD. However, the efficacy of TNF- $\alpha$ inhibitor monotherapy with regard to induction of clinical remission in randomized patients with refractory $C D$ was reportedly around $50 \%$ in 10 weeks. ${ }^{5}$ In addition, clinical responses to TNF- $\alpha$ inhibitors were often reduced during scheduled maintenance therapies, and flare-ups consequently occurred due to loss of response to IFX and ADA. ${ }^{5}$ These are limitations 
that make this treatment not always satisfactory. Accordingly, additional treatments that can induce clinical remission in these patients with refractory $\mathrm{CD}$, such as granulocyte and monocyte adsorptive apheresis (GMA) and AZA therapy, are needed. ${ }^{6-9}$ In addition, other therapeutic options with different mechanisms of action are required. Vedolizumab, a specific $\alpha 4 \beta 7$ integrin antagonist, is generally well tolerated, and a therapeutic option available for patients with moderate to severely active CD.

The present review focuses on therapeutic treatments that are effective and currently available for CD patients, or likely will be in the near future, and the advantages of management of refractory CD patients with combination therapy of TNF- $\alpha$ inhibitors plus AZA or intensive GMA.

\section{Currently available treatments}

\section{5-aminosalicylic acid}

A systematic review and meta-analysis of the effect of 5-ASA on $\mathrm{CD}^{10}$ demonstrated a trend toward a benefit with sulfasalazine over placebo with a relative risk (RR) of failure to achieve remission of 0.83 (95\% confidence interval [CI] 0.69-1.00), based on analyzed data showing that a remission (CD Activity Index $[\mathrm{CDAI}] \leq 150)$ was not achieved in 73 (57\%) of 128 patients randomized to receive sulfasalazine, compared with 93 (68.9\%) of 135 patients allocated to placebo. ${ }^{11,12}$

A recent systematic review of pertinent literature in the Cochrane database investigating the efficacy of sulfasalazine and mesalamine in inducing remission or clinical response in a total of 263 mild-to-moderate $C D$ patients randomized to sulfasalazine or placebo and 917 patients randomized to mesalamine or placebo demonstrated that sulfasalazine was of modest benefit in inducing remission, and 5-ASA appeared to be of little benefit in inducing remission. This is based on data showing that sulfasalazine was more likely to induce remission ( $\mathrm{RR} 1.38$; 95\% CI 1.02-1.87) compared with placebo; low-dose mesalamine (1-2 g/day) was not superior to placebo (RR 1.46; 95\% CI 0.89-2.40); and that high-dose mesalamine (3-4.5 g/day) was not superior to placebo for induction of remission (RR 2.02; 95\% CI $0.75-5.45$ ) or response (weighted mean difference -19.8 points; 95\% CI $-46.2,6.7){ }^{13}$

On the other hand, a systematic review investigating the efficacy of mesalazine for the maintenance of surgicallyinduced and medically-induced remission in 729 CD patients receiving surgical treatment and 1,305 CD patients receiving mesalazine demonstrated that variations in diversity of different 5-ASA formulations may be a key contributory factor in the clinical outcomes of patients with quiescent $\mathrm{CD}$ maintained on mesalazine, based on data showing that $\mathrm{pH}$ 7-dependent mesalazine treatment significantly reduced the risk of relapse in patients with either surgically-induced remission (odds ratio $0.28 ; 95 \%$ CI $0.12-0.65 ; P=0.0032$ ) or medically-induced remission (odds ratio $0.38 ; 95 \%$ CI $0.17-0.85 ; P=0.0113$ ), but that treatment with controlled-release mesalazine and pH 6-dependent mesalazine failed to show any significant advantage over placebo. In addition, therapeutic benefit was highest for $\mathrm{pH} 7$-dependent mesalazine (surgical 30.6\%, medical 22.8\%), compared with 6.9\% (surgical) and 6.4\% (medical), respectively, for controlled-release mesalazine, and $9.8 \%$ (surgical) and 4.4\% (medical), respectively, for $\mathrm{pH}$ 6-dependent mesalazine. Based on the above, sulfasalazine was of modest benefit in inducing remission and 5-ASA appeared to be of little benefit in inducing and maintaining medically-induced remission in $\mathrm{CD} .{ }^{14}$ However, $\mathrm{pH}$ 7-dependent mesalazine can be recommended for maintenance of surgically-induced and medically-induced remission.

\section{Corticosteroids}

Corticosteroids inhibit the expression of adhesion molecules and migration of inflammatory cells to target tissues, including the gut, thereby stemming the ability of these cells to modulate the immune response. ${ }^{15}$ A systematic review and meta-analysis of the efficacy of corticosteroids in CD demonstrated that corticosteroids may also be of benefit in inducing remission in patients with $\mathrm{CD}$, based on the analyzed data showing that $53(40.2 \%)$ of 132 patients assigned to oral glucocorticoids failed to achieve remission, compared with $93(68.9 \%)$ of 135 patients allocated to placebo. ${ }^{16}$ A recent meta-analysis of the Cochrane database literature investigating the efficacy of traditional corticosteroids (given orally or intravenously) for induction of remission in $\mathrm{CD}$ also demonstrated that corticosteroids were effective for induction of remission in a total of $267 \mathrm{CD}$ patients allocated to corticosteroids or placebo, particularly when used for more than 15 weeks, based on data showing that corticosteroids were significantly more effective than placebo at inducing remission in CD (RR 1.99; 95\% CI 1.51-2.64; $P<0.00001$ ), and that corticosteroids were more effective than 5-ASA at inducing remission in studies with long follow-up durations ( $>15$ weeks; RR 1.65; 95\% CI 1.33-2.03; $P<0.00001)$ in a total of 322 patients allocated to corticosteroid or 5-ASA. ${ }^{17}$ Based on the above, corticosteroids really are the first-line choice of treatment for inducing remission.

Budesonide, which maximizes the amount and action of corticosteroid available locally in the distal ileum and 
proximal colon but minimizes systemic availability, induces remission in active $C D$, based on an analysis showing that 192 (54.7\%) of 351 patients randomized to budesonide failed to achieve remission, compared with 81 (75.5\%) of 107 patients allocated to placebo, ${ }^{18,19}$ with a statistically significant effect in favor of budesonide (RR of failure to achieve remission 0.73 ; 95\% CI 0.63-0.84). ${ }^{16}$ However, budesonide was not superior to placebo in preventing CD relapse (RR 0.93; 95\% CI $0.83-1.04)^{16}$ because $200(62.7 \%)$ of 319 patients randomized to oral budesonide experienced a relapse of $\mathrm{CD}$, compared with $167(69.6 \%)$ of 240 patients allocated to placebo. ${ }^{20-24}$ In addition, glucocorticoids were superior to budesonide for CD remission, based on an analysis showing that 116 (38.2\%) of 304 patients receiving oral glucocorticoids failed to achieve remission, compared with $173(47.4 \%)$ of 365 patients receiving oral budesonide, with a statistically significant effect in favor of oral glucocorticoids (RR of failure to achieve remission 0.82; 95\% CI 0.68-0.98). ${ }^{16}$ Based on the above, budesonide is efficacious at inducing remission in active $\mathrm{CD}$, but is of no benefit in preventing relapse of quiescent $\mathrm{CD}$ and is less effective than glucocorticoids in inducing remission in active $\mathrm{CD}$.

\section{Leukocytapheresis}

Leukocytapheresis treatment depletes elevated and activated myeloid lineage leucocytes and has been associated with marked downregulation of inflammatory cytokines, including interleukin (IL)-1 $\beta$, IL-6, IL-8, and TNF- $\alpha$, which are released by myeloid leucocytes and lymphocytes, most likely via an upstream mechanism that involves adsorption of cytokine-producing cells. ${ }^{25,26}$ GMA (Adacolumn ${ }^{\mathrm{TM}}$, Jimro, Takasaki, Japan) and leukocytapheresis (Cellsorba ${ }^{\mathrm{TM}}$, Asahi Medical Company, Tokyo, Japan) are available in Europe and Japan for patients with active CD that may or may not be refractory to standard therapy, including TNF- $\alpha$ blockers. ${ }^{6,27,28}$ An open-label, multicenter prospective trial investigating the efficacy of weekly GMA showed that GMA was likely to be effective for inducing remission and improving quality of life, based on data showing that of 21 patients with active $\mathrm{CD}$ refractory to conventional therapy including 5-ASA, prednisolone, metronidazole, and nutrition therapy, and who received one GMA session per week for 5 consecutive weeks, six (28.5\%) were in clinical remission at week 7 and five $(23.8 \%)$ improved significantly. ${ }^{6}$ However, a randomized, double-blind, sham-controlled study investigating the efficacy of GMA demonstrated little effectiveness over a sham procedure for inducing clinical remission or response in patients with moderate-to-severe $\mathrm{CD}$, based on data showing that
$17.8 \%$ of 157 patients randomized to GMA achieved clinical remission compared with $19.2 \%$ of 78 patients allocated to sham control. ${ }^{29}$ However, further post hoc analyses demonstrated that patients with more severe disease activity (CDAI $>300$ ) at baseline were significantly more likely to respond to GMA, based on data showing that patients with CDAI $>300$ at baseline had a higher response to GMA compared with sham control (43.8\% versus $27.1 \%) .{ }^{30}$ Serious adverse side effects have been rare in patients receiving GMA.

\section{Azathioprine/6-mercaptopurine}

When 5-ASA and corticosteroids fail to control the inflammation associated with $\mathrm{CD}$, immunosuppressive therapy with purine analogs, ie, AZA/6-MP, is recommended. ${ }^{31}$ Thiopurines, such as AZA and 6-MP that are considered to act via active metabolites, and 6-thioguanine nucleotides (6-TGNs) are incorporated into cellular nucleotides and inhibit the proliferation of lymphocytes. ${ }^{32}$ A systematic review and meta-analysis demonstrated that AZA/6-MP appeared be of little benefit in inducing remission in active CD, based on data showing that $102(51.7 \%)$ of 197 patients randomized to $\mathrm{AZA} / 6-\mathrm{MP}$ failed to achieve remission compared with $115(62.8 \%)$ of 183 patients allocated to placebo, ${ }^{11,33-36}$ with no statistically significant benefit of AZA/6-MP over placebo (RR not in remission 0.87 ; 95\% CI 0.71-1.06). ${ }^{37}$ Further, AZA was not of benefit in preventing relapse in quiescent $\mathrm{CD}$ (RR $0.64 ; 95 \%$ CI $0.34-1.23$ ), ${ }^{37}$ based on data evaluating 27 (34.6\%) of 78 patients receiving AZA who experienced a relapse of CD compared with 53 (44.1\%) of 120 patients allocated to placebo. ${ }^{11,34}$ However, there was a statistically significant benefit for continuing AZA to prevent CD relapse (RR relapse with AZA 0.39; 95\% CI 0.21-0.74), based on data evaluating 163 patients in studies that assessed withdrawal of AZA from patients who were in remission for a mean 5 or 7.5 years on therapy. ${ }^{38-40}$ In addition, a very recent retrospective study investigating the success of planned thiopurine withdrawal in $129 \mathrm{CD}$ patients treated for a median duration of 6.0 years with thiopurines (AZA/6-MP), and had sustained corticosteroid-free clinical remission for at least 6 months, also demonstrated moderate to severe relapse in $23 \%$ of patients at 12 months and $39 \%$ of patients at 24 months. ${ }^{41}$ Based on the above, thiopurine analogs may prevent relapse in quiescent $C D$.

However, a prospective, double-blind trial of patients with newly diagnosed CD demonstrated that early AZA therapy was no more effective than placebo to achieve sustained corticosteroid-free remission, based on data showing that after 76 weeks of treatment, 30 (44.1\%; 95\% CI 32.9-55.9) 
of 68 patients randomized to AZA achieved sustained corticosteroid-free remission compared with 23 (36.5\%; 95\% CI 25.7-48.9) of 63 patients allocated to placebo, with no statistically significant benefit of AZA over placebo (absolute difference 7.6\%; 95\% CI -9.2, 24.4; $P=0.48$ ). ${ }^{42}$ This suggests that early use of an immunomodulator for the treatment of newly diagnosed CD patients was not likely to be of benefit.

AZA is a prodrug converted mid-stream to 6-TGN, an active metabolite that acts as a purine analog by inhibiting DNA synthesis and appears to trigger T-cell apoptosis. ${ }^{43,44} \mathrm{~A}$ recent meta-analysis investigating a more precise estimate of the association between 6-TGN levels and inflammatory bowel disease activity demonstrated that higher 6-TGN levels are associated with clinical remission, based on data showing that mean/median 6-TGN levels were higher in patients in remission than in those with active inflammatory bowel disease (pooled difference, $66 \mathrm{pmol} / 8 \times 10^{8}$ red blood cells; $95 \%$ CI $18-113 ; P=0.006)$, but with significant heterogeneity. ${ }^{45}$ This suggests the utility of checking 6-TGN levels in patients who have not responded to therapy in order to optimize their dose.

This systematic review also found no evidence of increased adverse events in patients taking purine analogs when compared with placebo. ${ }^{37}$ However, there was a trial reporting one patient dying of an infection associated with an immune-compromised state when taking AZA. ${ }^{39}$ This harmful event is associated with myelotoxicity in susceptible individuals, particularly those with low thiopurine methyltransferase activity. ${ }^{46}$ These drugs are also associated with a four- to sixfold increased risk of lymphoma ${ }^{47,48}$ and a two- to sixfold increase in non-melanoma skin cancer. ${ }^{49,50}$ Immunosuppressive therapy with AZA/6-MP is never without risk.

\section{Biologic therapy}

Inflammatory bowel disease is characterized by the extravasation of numerous inflammatory cells, including neutrophils and lymphocytes. Adhesion molecules, such as vascular cell adhesion molecule-1 and mucosal addressin cell adhesion molecule-1, and a component of their receptors, the integrin $\alpha 4$-subunit, mediate a series of immune responses and gut inflammation. ${ }^{51,52}$ TNF- $\alpha$ is a proinflammatory cytokine that activates inflammatory cells, upregulates adhesion molecules, and ultimately induces gut inflammation. TNF- $\alpha$ and integrin $\alpha 4$ act as key mediators of inflammation in inflammatory bowel disease.

\section{TNF- $\alpha$ blockade}

Pharmacologic management of CD targeting TNF- $\alpha$ currently consists of IFX and ADA, which are monoclonal antibodies against TNF- $\alpha$, and certolizumab, which consists of antigen-binding fragments of antibodies attached to polyethylene glycol. A systematic review and meta-analysis of the efficacy of anti-TNF- $\alpha$ antibodies in CD demonstrated that they are superior to placebo in inducing remission of luminal CD (RR of failure to achieve remission 0.87 ; $95 \% \mathrm{CI}$ $0.80-0.94),{ }^{53}$ based on data showing that remission of CD was not achieved in 1,142 (71.5\%) of 1,598 patients randomized to receive anti-TNF- $\alpha$ antibodies for 4-12 weeks, compared with $935(80.7 \%)$ of 1,158 patients allocated to placebo. . $^{3,854-59}$ In addition, anti-TNF- $\alpha$ antibodies were superior to placebo in preventing relapse of luminal CD (RR of relapse $0.71 ; 95 \%$ CI $0.65-0.76)^{53}$ since $472(55.9 \%)$ of 844 patients assigned to anti-TNF- $\alpha$ antibodies experienced disease relapse at 26-56 weeks, compared with 428 (78.4\%) of 546 patients randomized to placebo. ${ }^{2,4,5,60,61}$

Despite the efficacy of anti-TNF- $\alpha$ antibodies in inducing and maintaining remission, up to $46 \%$ of patients have been reported to experience loss of response to IFX and require dose escalation within 12 months of commencing therapy. ${ }^{62,63}$ Either shortening the interval or increasing the dose are often attempted to regain a response in these patients. A clinical trial assessing which of these strategies was optimal showed that dose-doubling is probably superior to halving the dosing interval, based on data demonstrating an early response to dose-escalation in $77 \%$ of patients in the dose-doubling group compared with $66 \%$ of patients in the interval-halving group (odds ratio 1.7; 95\% CI 0.8-3.4). Moreover, a sustained clinical response at 12 months post-escalation was maintained in $50 \%$ of patients in the dose-doubling group compared with $39 \%$ in the interval-halving group (odds ratio $1.5 ; 95 \%$ CI $0.8-2.9){ }^{64}$

\section{Natalizumab}

A systematic review and meta-analysis of the efficacy of natalizumab targeting integrin $\alpha 4$ demonstrated that natalizumab is superior to placebo in inducing remission of luminal CD (RR of failure to achieve remission $0.88 ; 95 \%$ CI 0.83-0.94), ${ }^{53}$ based on data showing that failure to achieve remission occurred in $810(65.4 \%)$ of 1,238 patients receiving natalizumab at 2-12 weeks compared with 412 (77.3\%) of 533 patients allocated to placebo. ${ }^{65-69}$ However, use of natalizumab in CD patients has been limited by the development in some patients of progressive multifocal leukoencephalopathy 
from an opportunistic brain infection caused by reactivation of latent John Cunningham polyomavirus. ${ }^{70}$

\section{Combination therapy with IFX plus AZA}

A clinical trial comparing the efficacy of IFX, AZA, and both agents combined for inducing and maintaining corticosteroidfree clinical remission in patients with active $C D$ showed that the combination of IFX and AZA or IFX monotherapy were more likely to induce clinical remission than AZA monotherapy. Of 169 patients receiving combination therapy, $96(56.8 \%)$ were in corticosteroid-free remission at week 26 , compared with $75(44.4 \%)$ of 169 patients receiving IFX alone $(P=0.02)$ and $51(30.3 \%)$ of 170 patients receiving AZA alone $(P<0.001$ for the comparison with combination therapy and $P=0.006$ for the comparison with IFX). In addition, at week 26, mucosal healing had occurred in 47 (43.9\%) of 107 patients receiving combination therapy, compared with $28(30.1 \%)$ of 93 patients receiving $\operatorname{IFX}(P=0.06)$ and $18(16.5 \%)$ of 109 patients receiving AZA $(P<0.001$ for the comparison with combination therapy and $P=0.02$ for the comparison with IFX). ${ }^{8}$ In addition, an open randomized trial comparing the efficacy of early use of combined immunosuppression with conventional management in patients with active $\mathrm{CD}$ who had not previously received glucocorticoids, antimetabolites, or IFX demonstrated that early combined immunosuppression was more effective than conventional treatment for induction of remission and reduction of corticosteroid use in patients with newly diagnosed $C D$, based on data showing that at week $26,39(60.0 \%)$ of 65 patients assigned to combined immunosuppression of IFX (three infusions at weeks $0,2,6$ ) with AZA were in corticosteroidfree and surgical resection-free remission, compared with $23(35.9 \%)$ of 64 patients assigned to conventional management who received corticosteroids, followed, in sequence, by AZA and IFX, for an absolute difference of $24.1 \%$ (95\% CI 7.3-40.8; $P=0.0062$ ). There were some adverse events in the combined immunosuppression group, such as a bowel resection and reversible loss of sensation from demyelination in the conus medullaris. However, there were no significant differences in occurrence of adverse events between the two groups.

Based on this evidence, anti-TNF- $\alpha$ antibodies such as IFX and ADA are more commonly used for active CD inflammation and are currently recommended in a "topdown" therapeutic fashion as first-line treatment, which is the opposite of the traditional pyramid of pharmacologic management, including 5-ASA and corticosteroids, which are prescribed in a "step-up" fashion as first-line treatment for patients with CD. ${ }^{71}$ Top-down therapy may be a better approach for many patients. However, $2 \%-5 \%$ of patients exposed to AZA/6-MP experience bone marrow suppression, and even in the absence of leukopenia, there is a risk of serious infection. ${ }^{72}$

In addition, a recent meta-analysis showed a fourfold increased risk of lymphoma in patients with inflammatory bowel disease treated using AZA/6-MP. ${ }^{73}$ Adverse events associated with the TNF- $\alpha$ inhibitors also include infectious complications, malignancy, demyelinating disorders, and autoimmunity. ${ }^{74}$

Therefore, the main concern with the top-down approach is the toxicities of the immunomodulators and TNF- $\alpha$ blockade in patients associated with infectious complications and an increased risk of lymphoma. It is unlikely that top-down therapy will be best for all patients given the underlying heterogeneity of the manifestations and severity of CD. Based on this concern, the concept of the "accelerated step-up" approach, which attempts to balance the risks and benefits of the currently available therapies with the risks of diseaserelated complications, has recently emerged; the proposal is that in patients with newly diagnosed moderate-to-severe $\mathrm{CD}, \mathrm{AZA}$ is continued with tapered corticosteroids for the maintenance of remission induced by corticosteroids in combination with AZA. ${ }^{34}$

The more potent medications, such as TNF- $\alpha$ inhibitors, are started on an on-demand basis if patients fail to respond and the disease flares. ${ }^{75}$ Thus, this "accelerated step-up" approach preserves the tactic of matching disease severity with treatment potency.

Interestingly, a double-blind, placebo-controlled trial investigating the advantage of combination maintenance therapy with methotrexate and IFX over IFX alone demonstrated that the combination therapy was no more effective than IFX alone in 126 patients with CD who had initiated prednisolone induction therapy within the preceding 6 weeks, based on data showing that by week 50 , the actuarial rate of treatment failure was $30.6 \%$ in the combination therapy group compared with $29.8 \%$ in the IFX alone group (hazard ratio $1.16 ; 95 \% \mathrm{CI} 0.62-2.17 ; P=0.63) .{ }^{76}$

\section{Combination therapy with ADA plus intensive GMA}

GMA depletes elevated/activated myeloid lineage leucocytes as sources of inflammatory cytokines and has been used to treat patients with $\mathrm{CD}$. In the clinical setting, as a nondrug 
intervention, weekly GMA when added to scheduled IFX maintenance therapy was effective in a CD patient with active disease while under IFX therapy. ${ }^{77}$ This was followed by a similar report indicating that the addition of intermittent weekly GMA to scheduled IFX maintenance was effective in a CD case also refractory to IFX alone. ${ }^{78}$ Moreover, a report investigated the efficacy of intensive GMA (two sessions per week) in combination with ADA as remission induction therapy in five consecutive cases with refractoriness to medications, including anti-TNF- $\alpha$ therapies such as IFX and ADA. At week 10 post-ADA treatments, clinical remission together with normal C-reactive protein levels were achieved in all five cases, while endoscopic findings, based on the simple endoscopic score for $\mathrm{CD}$, reflected marked improvement in three cases and partial improvement in two cases that had extensive deep longitudinal CD lesions (Figure 1 and Table 1). The CDAI and C-reactive protein values at baseline were $324 \pm 118$ and $4.9 \pm 3.3 \mathrm{mg} / \mathrm{dL}$, respectively; the corresponding values after treatment were $100 \pm 28(P=0.024)$ and $0.2 \pm 0.2 \mathrm{mg} / \mathrm{dL}(P=0.038$, Figure 2$)$. All five cases responded well to combination therapy of intensive GMA plus ADA, achieving clinical remission, normal serum $\mathrm{C}$-reactive protein levels, and marked healing of their CD lesions. No adverse events were observed in that study. ${ }^{7}$

In clinical settings, ADA is expected to induce sustained clinical remission in patients with moderate to severe active luminal CD. However, the rates of clinical remission for biologic therapy-naïve patients has not been impressive, and have been at best about $36 \%$ and $50 \%$ at 4 and 10 weeks, respectively., 3 Likewise, its efficacy for patients with loss of response or intolerance to IFX was $21 \%$ at 4 weeks. ${ }^{57}$ Therefore, the efficacy outcomes for ADA monotherapy in patients with active CD have been limited. This suggests that in order to achieve sustained clinical remission in the majority of $\mathrm{CD}$ patients, biologic-naïve patients, or those with the loss of response to TNF- $\alpha$ antagonists, new treatment strategies are desirable.

Based on the above, combination therapy with ADA plus intensive GMA is useful to induce clinical remission in patients with active CD. However, a randomized, prospective study is needed to fully evaluate the efficacy of combination therapy with ADA plus intensive GMA.

\section{Vedolizumab}

The GEMINI 2 clinical trial ${ }^{79}$ investigating the efficacy of vedolizumab, a humanized immunoglobulin G1 monoclonal antibody to integrin $\alpha 4 \beta 7$, demonstrated that patients with active $C D$ treated using vedolizumab were more likely than patients receiving placebo to have a remission at week 6 and that patients with a response to induction therapy who continued to receive vedolizumab were more likely to be in remission at week 52 , based on data showing that $14.5 \%$ of the 220 patients receiving vedolizumab of the 368 patients who were randomly assigned to receive vedolizumab or placebo, of whom approximately $50 \%$ had previously received TNF antagonist therapy, were in clinical remission at week 6 , compared with $6.8 \%$ of the 148 receiving placebo, with a significant benefit of vedlolizumab over placebo. A subsequent randomized trial of maintenance therapy with vedolizumab every 8 or 4 weeks, or placebo, in a total of 461 patients (96 patients were randomly assigned to receive vedolizumab and had clinical remission at week 6 , plus 365 patients received open-label vedolizumab and had clinical remission at week 6) demonstrated that $39.0 \%$ and $36.4 \%$ of those assigned
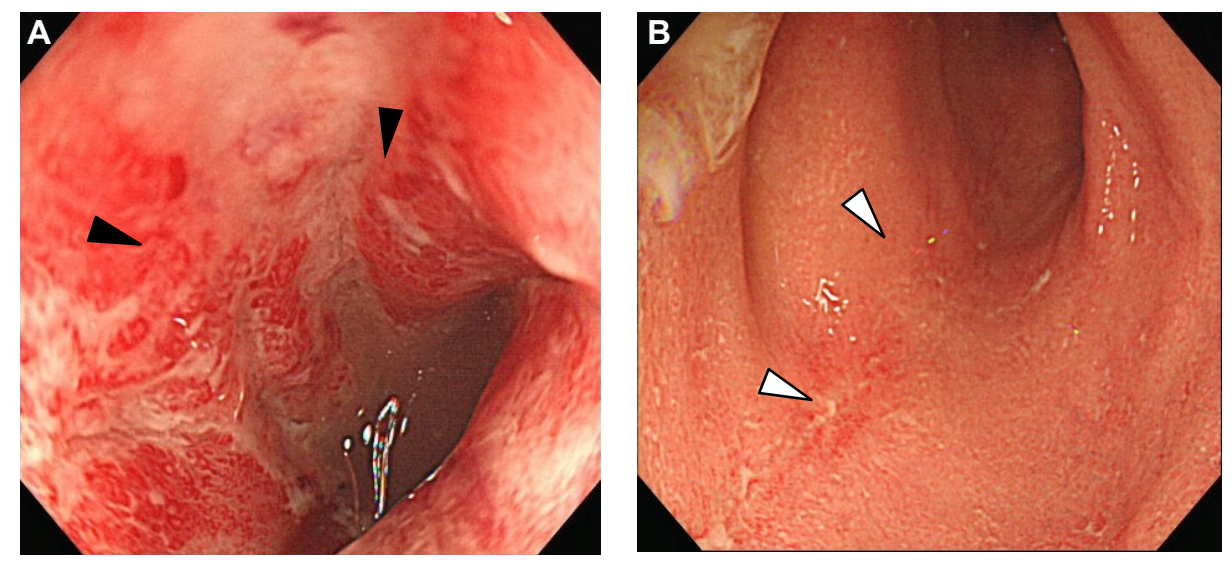

Figure I Endoscopic findings at baseline (A) and at week 10 (B).

Notes: (A) Black arrowheads indicate the active ulcer. (B) White arrowheads indicate the ulcer scar. Copyright (C) 2012. The Japanese Society of Internal Medicine. Figure adapted from Ozeki K, Tanida S, Mizushima T, et al. Combination therapy with adalimumab plus intensive granulocyte and monocyte adsorptive apheresis induced clinical remission in a Crohn's disease patient with the loss of response to scheduled adalimumab maintenance therapy: a case report. Internal Medicine. 20I2;5 (6):595-599.9 
Table I Endoscopic assessment outcomes based on SES-CD in all five cases

\begin{tabular}{lll}
\hline Case number & Baseline & 10 weeks post five ADA injections \\
\hline 1 & 13 & 0 \\
2 & 5 & 2 \\
3 & 13 & 4 \\
4 & 14 & 10 \\
5 & 23 & 14 \\
\hline
\end{tabular}

Note: Copyright @ $\odot 2012$ by S. Karger AG, Basel. Adapted from Ozeki K, Tanida S, Mizoshita T, et al. Combination therapy with intensive granulocyte and monocyte adsorptive apheresis plus adalimumab: therapeutic outcomes in 5 cases with refractory Crohn's disease. Case Rep Gastroenterol. 2012;6(3):765-77I. .7

Abbreviation: ADA, adalimumab; CD, Crohn's disease; $S E S-C D$, simple endoscopic score for CD.

to vedolizumab every 8 or 4 weeks, respectively, were in clinical remission at week 52 , compared with $21.6 \%$ allocated to placebo; the difference was statistically significant. In addition, a placebo-controlled, double-blind, Phase III trial evaluating the efficacy and safety of vedolizumab as induction therapy in 315 patients with refractory $\mathrm{CD}$, in whom previous therapy with TNF antagonists had failed, demonstrated that vedolizumab was no more effective than placebo in inducing clinical remission at week 6 in $\mathrm{CD}$ patients who had experienced previous TNF- $\alpha$ antagonist failure, based on data showing that $15.2 \%$ of those receiving vedolizumab and $12.1 \%$ of those receiving placebo were in remission at week 6 (RR 1.2; 95\% CI 0.7-2.2; $P=0.433$ ). ${ }^{80}$ Regarding safety concerns, the incidence of serious adverse events was higher among patients who received vedolizumab than among those who received placebo ( $24.4 \%$ versus $15.3 \%$, respectively), with five deaths from sepsis and myocarditis. No cases of progressive multifocal leukoencephalopathy were observed during this trial. The death rate in this study was similar to the crude death rates associated with use of other biologic medications..$^{2,5,56,68}$

Based on this evidence, vedolizumab therapy is an effective treatment for patients with active $\mathrm{CD}$, but may not be more effective than placebo in inducing clinical remission among CD patients who have experienced previous TNF- $\alpha$ antagonist failure.

\section{Treatments available in the near future}

Ustekinumab, a human immunoglobulin G1 monoclonal antibody, blocks the biologic activity of IL-12 and IL-23 through their common p40 subunit by inhibiting receptors for these two cytokines on T-cells, natural killer cells, and antigen-presenting cells. ${ }^{81}$ A Phase IIa study ${ }^{82}$ including a double-blind trial demonstrated that ustekinumab had efficacy in 104 patients with moderate-to-severe CD, particularly in those who had previously received IFX. Fifty-three percent of 51 patients in the combined ustekinumab group had a clinical response at weeks 4 and 6, compared with $30 \%$ of 53 patients in the combined placebo group $(P=0.02)$, and $49 \%$ in the combined ustekinumab group at week 8 compared with $40 \%$ in the combined placebo group $(P=0.34)$. In 49 patients

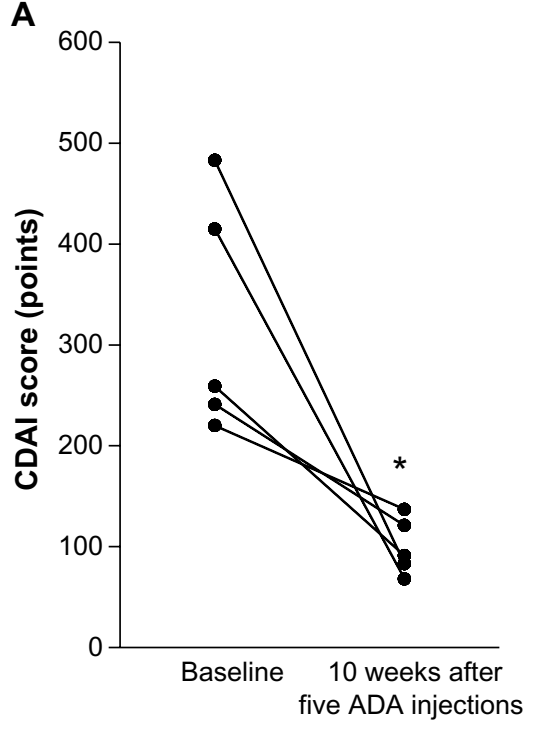

\section{B}

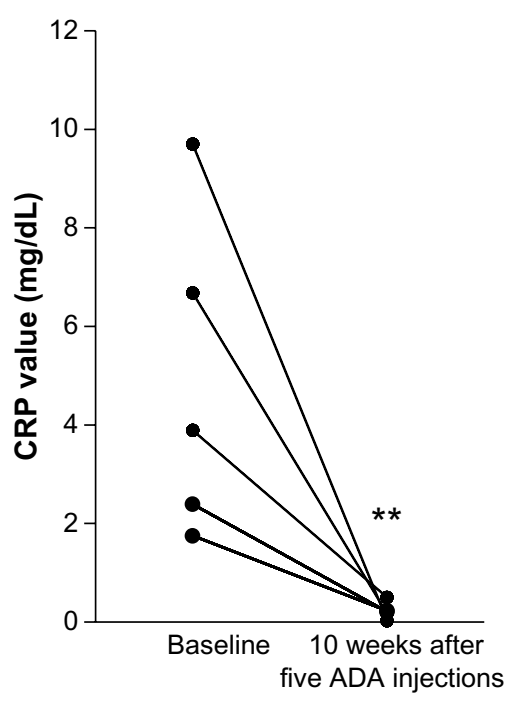

Figure 2 The overall changes in the CDAl scores (A) and CRP levels (B) from baseline to 10 weeks after five ADA injections for all five cases in this study.

Note: $(\mathbf{A}) * P=0.024$ vs baseline; $N=5$. (B) $* * P=0.038$ vs baseline; $N=5$. The comparisons were made by using the Student's $t$-test. Copyright $(2012$ by $S$. Karger AG, Basel. Adapted from Ozeki K, Tanida S, Mizoshita T, et al. Combination therapy with intensive granulocyte and monocyte adsorptive apheresis plus adalimumab: therapeutic outcomes in 5 cases with refractory Crohn's disease. Case Rep Gastroenterol. 20I 2;6(3):765-77I. ${ }^{7}$

Abbreviations: ADA, adalimumab; CRP, C-reactive protein; CDAl, Crohn's disease activity index. 
treated previously with IFX, the rates of clinical response to ustekinumab were greater than those for placebo $(P<0.05)$ at every visit through week 8 . There was no increase in the number of adverse events or serious adverse events in patients receiving ustekinumab through week 8 when compared with placebo.

In addition, a randomized, double-blind, placebocontrolled Phase IIb trial ${ }^{83}$ investigating the efficacy of ustekinumab in patients with moderate-to-severe CD resistant to anti-TNF treatment, demonstrated that patients had an increased rate of response to induction with ustekinumab, compared with placebo, and that patients with an initial response to ustekinumab had significantly increased rates of response and remission on ustekinumab as maintenance therapy, based on data showing that in 526 patients who were randomly assigned to receive 1,3 , or $6 \mathrm{mg} / \mathrm{kg}$ of ustekinumab or placebo, the proportion of patients in clinical response at week 6 in the induction phase was significantly greater among patients receiving $6 \mathrm{mg} / \mathrm{kg}$ of ustekinumab than among those receiving placebo $(39.7 \%$ versus $23.5 \%, 95 \%$ CI $5.1-27.3 ; P=0.005)$, and that the proportion of patients in clinical remission at week 22 was significantly greater in the ustekinumab group than in the placebo group (69.4\% versus 42.5\%, 95\% CI 11.5-42.5; $P<0.001)$. Moreover, among patients with a response to ustekinumab in the induction phase, $41.7 \%$ of those receiving $90 \mathrm{mg}$ of ustekinumab in the maintenance phase were in clinical remission at week 22, compared with $27.4 \%$ of patients receiving placebo (95\% CI $2.0-27.1 ; P=0.03)$. Serious infections occurred in seven patients (six receiving ustekinumab) during induction and eleven patients (four receiving ustekinumab) during maintenance. Basal cell carcinoma was observed in one patient receiving ustekinumab.

Based on this evidence, biologic therapy with ustekinumab is an effective treatment for patients with refractory $\mathrm{CD}$ that is resistant to TNF- $\alpha$ antagonists.

\section{Conclusion and perspective}

Combination therapy of ADA plus intensive GMA, or IFX plus AZA, is considered to be useful for the treatment of patients with refractory $\mathrm{CD}$ due to the high rate of induction of remission. These therapeutic strategies are not always satisfactory and are limited. To address this limitation, many biological agents, such as monoclonal antibodies and small molecules that target the surplus or excessive activity of the immune system, are currently being developed. Much progress has been made in understanding the pathogenesis of $\mathrm{CD}$, and as a result many potentially useful treatments will emerge and be available in the future.

\section{Disclosure}

The authors report no conflicts of interest in this work.

\section{References}

1. Van Deventer SJ. Tumour necrosis factor and Crohn's disease. Gut. 1997;40(4):443-448.

2. Hanauer SB, Feagan BG, Lichtenstein GR, et al. Maintenance infliximab for Crohn's disease: the ACCENT I randomised trial. Lancet. 2002;359(9317):1541-1549.

3. Hanauer SB, Sandborn WJ, Rutgeerts P, et al. Human anti-tumor necrosis factor monoclonal antibody (adalimumab) in Crohn's disease: the CLASSIC-I trial. Gastroenterology. 2006;130(2):323-333.

4. Sandborn WJ, Hanauer SB, Rutgeerts P, et al. Adalimumab for maintenance treatment of Crohn's disease: results of the CLASSIC II trial. Gut. 2007;56(9):1232-1239.

5. Colombel JF, Sandborn WJ, Rutgeerts P, et al. Adalimumab for maintenance of clinical response and remission in patients with Crohn's disease: the CHARM trial. Gastroenterology. 2007;132(1): $52-65$.

6. Fukuda Y, Matsui T, Suzuki Y, et al. Adsorptive granulocyte and monocyte apheresis for refractory Crohn's disease: an open multicenter prospective study. J Gastroenterol. 2004;39(12):1158-1164.

7. Ozeki K, Tanida S, Mizoshita T, et al. Combination therapy with intensive granulocyte and monocyte adsorptive apheresis plus adalimumab: therapeutic outcomes in 5 cases with refractory Crohn's disease. Case Rep Gastroenterol. 2012;6(3):765-771.

8. Colombel JF, Sandborn WJ, Reinisch W, et al. Infliximab, azathioprine, or combination therapy for Crohn's disease. $N$ Engl J Med. 2010;362(15):1383-1395.

9. Ozeki K, Tanida S, Mizushima T, et al. Combination therapy with adalimumab plus intensive granulocyte and monocyte adsorptive apheresis induced clinical remission in a Crohn's disease patient with the loss of response to scheduled adalimumab maintenance therapy: a case report. Intern Med. 2012;51(6):595-599.

10. Ford AC, Kane SV, Khan KJ, et al. Efficacy of 5-aminosalicylates in Crohn's disease: systematic review and meta-analysis. $\mathrm{Am} \mathrm{J}$ Gastroenterol. 2011;106(4):617-629.

11. Summers RW, Switz DM, Sessions JT Jr, et al. National Cooperative Crohn's Disease Study: results of drug treatment. Gastroenterology. 1979;77(4 Pt 2):847-869.

12. Malchow H, Ewe K, Brandes JW, et al. European Cooperative Crohn's Disease Study (ECCDS): results of drug treatment. Gastroenterology. 1984;86(2):249-266.

13. Lim WC, Hanauer S. Aminosalicylates for induction of remission or response in Crohn's disease. Cochrane Database Syst Rev. 2010;12: 008870

14. Steinhart AH, Forbes A, Mills EC, Rodgers-Gray BS, Travis SP. Systematic review: the potential influence of mesalazine formulation on maintenance of remission in Crohn's disease. Aliment Pharmacol Ther. 2007;25(12):1389-1399.

15. Hayashi R, Wada H, Ito K, Adcock IM. Effects of glucocorticoids on gene transcription. Eur J Pharmacol. 2004;500(1-3):51-62.

16. Ford AC, Bernstein CN, Khan KJ, et al. Glucocorticosteroid therapy in inflammatory bowel disease: systematic review and meta-analysis. Am J Gastroenterol. 2011;106(4):590-599.

17. Benchimol EI, Seow CH, Steinhart AH, Griffiths AM. Traditional corticosteroids for induction of remission in Crohn's disease. Cochrane Database Syst Rev. 2008;2:006792.

18. Greenberg GR, Feagan BG, Martin F, et al. Oral budesonide for active Crohn's disease. Canadian Inflammatory Bowel Disease Study Group. N Engl J Med. 1994;331(13):836-841. 
19. Tremaine WJ, Hanauer SB, Katz S, et al. Budesonide CIR capsules (once or twice daily divided-dose) in active Crohn's disease: a randomized placebo-controlled study in the United States. Am J Gastroenterol. 2002;97(7):1748-1754.

20. Greenberg GR, Feagan BG, Martin F, et al. Oral budesonide as maintenance treatment for Crohn's disease: a placebo-controlled, doseranging study. Canadian Inflammatory Bowel Disease Study Group. Gastroenterology. 1996;110(1):45-51.

21. Lofberg R, Rutgeerts P, Malchow H, et al. Budesonide prolongs time to relapse in ileal and ileocaecal Crohn's disease. A placebo controlled one year study. Gut. 1996;39(1):82-86.

22. Ferguson A, Campieri M, Doe W, Persson T, Nygard G. Oral budesonide as maintenance therapy in Crohn's disease - results of a 12-month study. Global Budesonide Study Group. Aliment Pharmacol Ther. 1998;12(2):175-183.

23. Gross V, Andus T, Ecker KW, et al. Low dose oral $\mathrm{pH}$ modified release budesonide for maintenance of steroid induced remission in Crohn's disease. The Budesonide Study Group. Gut. 1998;42(4):493-496.

24. Hanauer S, Sandborn WJ, Persson A, Persson T. Budesonide as maintenance treatment in Crohn's disease: a placebo-controlled trial. Aliment Pharmacol Ther. 2005;21(4):363-371.

25. Kashiwagi N, Hirata I, Kasukawa R. A role for granulocyte and monocyte apheresis in the treatment of rheumatoid arthritis. Ther Apher. 1998;2(2):134-141.

26. Saniabadi AR, Hanai H, Takeuchi K, et al. Adacolumn, an adsorptive carrier based granulocyte and monocyte apheresis device for the treatment of inflammatory and refractory diseases associated with leukocytes. Ther Apher Dial. 2003;7(1):48-59.

27. Domenech E, Hinojosa J, Esteve-Comas M, et al. Granulocytapheresis in steroid-dependent inflammatory bowel disease: a prospective, open, pilot study. Aliment Pharmacol Ther. 2004;20(11-12):1347-1352.

28. Matsui T, Nishimura T, Matake H, Ohta T, Sakurai T, Yao T. Granulocytapheresis for Crohn's disease: a report on seven refractory patients. Am J Gastroenterol. 2003;98(2):511-512.

29. Sands BE, Katz S, Wolf DC, et al. A randomised, double-blind, shamcontrolled study of granulocyte/monocyte apheresis for moderate to severe Crohn's disease. Gut. 2013;62(9):1288-1294.

30. Eaden JA, Ford AC. Efficacy of granulocyte/monocyte apheresis for moderate to severe Crohn's disease. Gut. 2013;62(4):653.

31. Lichtenstein GR, Hanauer SB, Sandborn WJ; Practice Parameters Committee of American College of G. Management of Crohn's disease in adults. Am J Gastroenterol. 2009,104(2):465-483.

32. Sahasranaman S, Howard D, Roy S. Clinical pharmacology and pharmacogenetics of thiopurines. Eur J Clin Pharmacol. 2008;64(8): 753-767.

33. Ewe K, Press AG, Singe CC, et al. Azathioprine combined with prednisolone or monotherapy with prednisolone in active Crohn's disease. Gastroenterology. 1993;105(2):367-372.

34. Candy S, Wright J, Gerber M, Adams G, Gerig M, Goodman R. A controlled double blind study of azathioprine in the management of Crohn's disease. Gut. 1995;37(5):674-678.

35. Reinisch W, Panes J, Lemann M, et al. A multicenter, randomized, double-blind trial of everolimus versus azathioprine and placebo to maintain steroid-induced remission in patients with moderate-tosevere active Crohn's disease. Am J Gastroenterol. 2008;103(9): 2284-2292.

36. Oren R, Moshkowitz M, Odes S, et al. Methotrexate in chronic active Crohn's disease: a double-blind, randomized, Israeli multicenter trial. Am J Gastroenterol. 1997;92(12):2203-2209.

37. Khan KJ, Dubinsky MC, Ford AC, Ullman TA, Talley NJ, Moayyedi P. Efficacy of immunosuppressive therapy for inflammatory bowel disease: a systematic review and meta-analysis. Am J Gastroenterol. 2011;106(4):630-642.

38. Lemann M, Mary JY, Colombel JF, et al. A randomized, doubleblind, controlled withdrawal trial in Crohn's disease patients in long-term remission on azathioprine. Gastroenterology. 2005;128(7): 1812-1818.
39. O’Donoghue DP, Dawson AM, Powell-Tuck J, Bown RL, Lennard-Jones JE. Double-blind withdrawal trial of azathioprine as maintenance treatment for Crohn's disease. Lancet. 1978;2(8097): 955-957.

40. Vilien M, Dahlerup JF, Munck LK, Norregaard P, Gronbaek K, Fallingborg J. Randomized controlled azathioprine withdrawal after more than two years treatment in Crohn's disease: increased relapse rate the following year. Aliment Pharmacol Ther. 2004;19(11):1147-1152.

41. Kennedy NA, Kalla R, Warner B, et al. Thiopurine withdrawal during sustained clinical remission in inflammatory bowel disease: relapse and recapture rates, with predictive factors in 237 patients. Aliment Pharmacol Ther. 2014;40(11-12):1313-1323.

42. Panes J, Lopez-Sanroman A, Bermejo F, et al. Early azathioprine therapy is no more effective than placebo for newly diagnosed Crohn's disease. Gastroenterology. 2013;145(4):766-774.

43. Maltzman JS, Koretzky GA. Azathioprine: old drug, new actions. J Clin Invest. 2003;111(8):1122-1124.

44. Tiede I, Fritz G, Strand S, et al. CD28-dependent Rac1 activation is the molecular target of azathioprine in primary human CD4+ T lymphocytes. J Clin Invest. 2003;111(8):1133-1145.

45. Osterman MT, Kundu R, Lichtenstein GR, Lewis JD. Association of 6-thioguanine nucleotide levels and inflammatory bowel disease activity: a meta-analysis. Gastroenterology. 2006;130(4): 1047-1053.

46. Gisbert JP, Nino P, Rodrigo L, Cara C, Guijarro LG. Thiopurine methyltransferase (TPMT) activity and adverse effects of azathioprine in inflammatory bowel disease: long-term follow-up study of 394 patients. Am J Gastroenterol. 2006;101(12):2769-2776.

47. Armstrong RG, West J, Card TR. Risk of cancer in inflammatory bowel disease treated with azathioprine: a UK population-based case-control study. Am J Gastroenterol. 2010;105(7):1604-1609.

48. Beaugerie L, Brousse N, Bouvier AM, et al. Lymphoproliferative disorders in patients receiving thiopurines for inflammatory bowel disease: a prospective observational cohort study. Lancet. 2009;374(9701) $1617-1625$

49. Long MD, Martin CF, Pipkin CA, Herfarth HH, Sandler RS, Kappelman MD. Risk of melanoma and nonmelanoma skin cancer among patients with inflammatory bowel disease. Gastroenterology. 2012;143(2):390-399.

50. Peyrin-Biroulet L, Khosrotehrani K, Carrat F, et al. Increased risk for nonmelanoma skin cancers in patients who receive thiopurines for inflammatory bowel disease. Gastroenterology. 2011;141(5):1621-1628.

51. Binion DG, West GA, Ina K, Ziats NP, Emancipator SN, Fiocchi C. Enhanced leukocyte binding by intestinal microvascular endothelial cells in inflammatory bowel disease. Gastroenterology. 1997;112(6): 1895-1907.

52. Farstad IN, Halstensen TS, Kvale D, Fausa O, Brandtzaeg P. Topographic distribution of homing receptors on $\mathrm{B}$ and $\mathrm{T}$ cells in human gutassociated lymphoid tissue: relation of L-selectin and integrin alpha 4 beta 7 to naive and memory phenotypes. Am J Pathol. 1997; 150(1): 187-199.

53. Ford AC, Sandborn WJ, Khan KJ, Hanauer SB, Talley NJ, Moayyedi P. Efficacy of biological therapies in inflammatory bowel disease: systematic review and meta-analysis. Am J Gastroenterol. 2011;106(4) 644-659.

54. Watanabe M, Hibi T, Lomax KG, et al. Adalimumab for the induction and maintenance of clinical remission in Japanese patients with Crohn's disease. J Crohns Colitis. 2012;6(2):160-173.

55. Targan SR, Hanauer SB, van Deventer SJ, et al. A short-term study of chimeric monoclonal antibody cA2 to tumor necrosis factor alpha for Crohn's disease. Crohn's Disease cA2 Study Group. $N$ Engl J Med. 1997;337(15):1029-1035.

56. Sandborn WJ, Feagan BG, Stoinov S, et al. Certolizumab pegol for the treatment of Crohn's disease. N Engl J Med. 2007;357(3):228-238.

57. Sandborn WJ, Rutgeerts P, Enns R, et al. Adalimumab induction therapy for Crohn disease previously treated with infliximab: a randomized trial. Ann Intern Med. 2007;146(12):829-838. 
58. Lemann M, Mary JY, Duclos B, et al. Infliximab plus azathioprine for steroid-dependent Crohn's disease patients: a randomized placebocontrolled trial. Gastroenterology. 2006;130(4):1054-1061.

59. Schreiber S, Rutgeerts P, Fedorak RN, et al. A randomized, placebocontrolled trial of certolizumab pegol (CDP870) for treatment of Crohn's disease. Gastroenterology. 2005;129(3):807-818.

60. Rutgeerts P, D’Haens G, Targan S, et al. Efficacy and safety of retreatment with anti-tumor necrosis factor antibody (infliximab) to maintain remission in Crohn's disease. Gastroenterology. 1999;117(4): 761-769.

61. Schreiber S, Khaliq-Kareemi M, Lawrance IC, et al. Maintenance therapy with certolizumab pegol for Crohn's disease. $N$ Engl J Med. 2007;357(3):239-250.

62. Ben-Horin S, Chowers Y. Review article: loss of response to anti-TNF treatments in Crohn's disease. Aliment Pharmacol Ther. 2011;33(9): 987-995.

63. Gisbert JP, Panes J. Loss of response and requirement of infliximab dose intensification in Crohn's disease: a review. Am J Gastroenterol. 2009;104(3):760-767.

64. Katz L, Gisbert JP, Manoogian B, et al. Doubling the infliximab dose versus halving the infusion intervals in Crohn's disease patients with loss of response. Inflamm Bowel Dis. 2012;18(11):2026-2033.

65. Targan SR, Feagan BG, Fedorak RN, et al. Natalizumab for the treatment of active Crohn's disease: results of the ENCORE Trial. Gastroenterology. 2007;132(5):1672-1683.

66. Sands BE, Kozarek R, Spainhour J, et al. Safety and tolerability of concurrent natalizumab treatment for patients with Crohn's disease not in remission while receiving infliximab. Inflamm Bowel Dis. 2007;13(1): $2-11$.

67. Ghosh S, Goldin E, Gordon FH, et al. Natalizumab for active Crohn's disease. N Engl J Med. 2003;348(1):24-32.

68. Sandborn WJ, Colombel JF, Enns R, et al. Natalizumab induction and maintenance therapy for Crohn's disease. N Engl J Med. 2005;353(18): 1912-1925.

69. Gordon FH, Lai CW, Hamilton MI, et al. A randomized placebocontrolled trial of a humanized monoclonal antibody to alpha4 integrin in active Crohn's disease. Gastroenterology. 2001;121(2):268-274.

70. Bloomgren G, Richman S, Hotermans C, et al. Risk of natalizumabassociated progressive multifocal leukoencephalopathy. N Engl J Med. 2012;366(20):1870-1880.

71. D’Haens G, Baert F, van Assche G, et al. Early combined immunosuppression or conventional management in patients with newly diagnosed Crohn's disease: an open randomised trial. Lancet. 2008;371(9613): 660-667.

72. Lichtenstein GR, Abreu MT, Cohen R, Tremaine W; American Gastroenterological Association. American Gastroenterological Association Institute technical review on corticosteroids, immunomodulators, and infliximab in inflammatory bowel disease. Gastroenterology. 2006; 130(3):940-987.
73. Kandiel A, Fraser AG, Korelitz BI, Brensinger C, Lewis JD. Increased risk of lymphoma among inflammatory bowel disease patients treated with azathioprine and 6-mercaptopurine. Gut. 2005;54(8): 1121-1125.

74. Clark M, Colombel JF, Feagan BC, et al. American Gastroenterological Association consensus development conference on the use of biologics in the treatment of inflammatory bowel disease, June 21-23, 2006. Gastroenterology. 2007;133(1):312-339.

75. Shergill AK, Terdiman JP. Controversies in the treatment of Crohn's disease: the case for an accelerated step-up treatment approach. World J Gastroenterol. 2008;14(17):2670-2677.

76. Feagan BG, McDonald JW, Panaccione R, et al. Methotrexate in combination with infliximab is no more effective than infliximab alone in patients with Crohn's disease. Gastroenterology. 2014;146(3): 681-688.

77. Gonzalez Carro P, Perez Roldan F, Roncero Garcia Escribano O, Lafuente R, Legaz Huidobro ML, Amigo Echenagusia A. Case report: therapy with granulocyte apheresis and infliximab for refractory Crohn's disease. J Clin Apher. 2006;21(4):249-251.

78. Fukunaga K, Yokoyama Y, Kamikozuru K, et al. Selective depletion of peripheral granulocyte/monocyte enhances the efficacy of scheduled maintenance infliximab in Crohn's disease. J Clin Apher. 2010;25(4): 226-228.

79. Sandborn WJ, Feagan BG, Rutgeerts P, et al. Vedolizumab as induction and maintenance therapy for Crohn's disease. $N$ Engl J Med. 2013; 369(8):711-721.

80. Sands BE, Feagan BG, Rutgeerts P, et al. Effects of vedolizumab induction therapy for patients with Crohn's disease in whom tumor necrosis factor antagonist treatment failed. Gastroenterology. 2014;147(3): 618-627.

81. Benson JM, Peritt D, Scallon BJ, et al. Discovery and mechanism of ustekinumab: a human monoclonal antibody targeting interleukin-12 and interleukin-23 for treatment of immune-mediated disorders. MAbs. 2011;3(6):535-545.

82. Sandborn WJ, Feagan BG, Fedorak RN, et al. A randomized trial of ustekinumab, a human interleukin-12/23 monoclonal antibody, in patients with moderate-to-severe Crohn's disease. Gastroenterology. 2008,135(4):1130-1141.

83. Sandborn WJ, Gasink C, Gao LL, et al. Ustekinumab induction and maintenance therapy in refractory Crohn's disease. N Engl J Med. 2012; 367(16):1519-1528.
Clinical and Experimental Gastroenterology

\section{Publish your work in this journal}

Clinical and Experimental Gastroenterology is an international, peerreviewed, open access journal, publishing all aspects of gastroenterology in the clinic and laboratory, including: Pathology, pathophysiology of gastrointestinal disease; Investigation and treatment of gastointestinal disease; Pharmacology of drugs used in the alimentary tract;

\section{Dovepress}

Immunology/genetics/genomics related to gastrointestinal disease. This journal is indexed on CAS. The manuscript management system is completely online and includes a very quick and fair peer-review system. Visit http://www.dovepress.com/testimonials.php to read real quotes from published authors. 